\title{
Persepsi pengunjung terhadap kualitas wayfinding sebagai elemen interior di Poliklinik RSIA Limijati, Bandung
}

\author{
Annisa Andrivina* \\ Magister Desain, Fakultas Seni Rupa dan Desain, Institut Teknologi Bandung, Bandung, Indonesia
}

\begin{abstract}
Patient and visitor's satisfaction is an indicator of the healthcare facility's quality in hospital. One of the healthcare facilities in hospital is polyclinic area. Indonesia is committed to building a manufacturing industry that is globally competitive through accelerating the implementation of Industry 4.0. In this industrial revolution, there was a big leap where information and communication technology was fully utilized. The health industry also experienced this impact. The digital era in health facilities is a challenge to be better at providing health services to the community. Patient and visitor of health facility are those who are not familiar with the hospital environment and often have poor emotional and physical conditions. Therefore, it required a physical environment that can support the convenience of visitors, especially in the ease of finding the destination. One of the parameters of "design that cares" is to providing convenience for patient and visitor in finding purpose (wayfinding) and oriented in the building. This study is in the form of library research and uses descriptive analysis methods that take samples of patients and visitors of the RSIA Limijati Polyclinic, Bandung. Data were collected by accidental sampling technique through interview, observation, and questionnaire. This research is expected to provide solution to wayfinding design problem related to hospital user's characteristics, especially polyclinic area.
\end{abstract}

Key words: polyclinic, orientation, wayfinding

\begin{abstract}
Abstrak
Kepuasan pasien dan pengunjung merupakan indikator mutu pelayanan kesehatan di rumah sakit. Salah satu diantaranya ialah pelayanan di area poliklinik. Indonesia berkomitmen untuk membangun industri manufaktur yang berdaya saing global melalui percepatan implementasi Industri 4.0. Pada revolusi industri ini terjadi lompatan besar di mana teknologi informasi dan komunikasi dimanfaatkan sepenuhnya. Industri kesehatan juga mengalami dampak tersebut. Era digital dalam fasilitas kesehatan menjadi tantangan sekaligus peluang untuk menjadi lebih baik dalam memberikan pelayanan kesehatan kepada masyarakat. Pasien dan pengunjung fasilitas kesehatan adalah mereka yang tidak familiar dengan lingkungan rumah sakit dan sering memiliki kondisi emosional dan fisik yang buruk. Oleh karena itu, dibutuhkan lingkungan fisik yang dapat mendukung kenyamanan pengunjung, terutama dalam kemudahan untuk mencari tempat tujuan. Salah satu parameter "desain yang peduli" ialah memberikan kemudahan bagi pengunjung dalam menemukan tujuan (wayfinding) dan berorientasi di dalam bangunan. Penelitian ini berbentuk penelitian kepustakaan (library research) dan menggunakan metode analisis deskriptif yang mengambil sampel pasien dan pengunjung Poliklinik RSIA Limijati, Bandung. Data dikumpulkan dengan teknik accidental sampling melalui wawancara, observasi, dan kuesioner. Penelitian ini diharapkan dapat memberikan solusi terhadap permasalahan desain wayfinding yang berhubungan dengan karakteristik pengguna rumah sakit, terutama area poliklinik.
\end{abstract}

Kata kunci: poliklinik, orientasi, wayfinding

\section{Pendahuluan}

Fasilitas kesehatan merupakan sebuah lingkungan binaan skala besar yang memiliki permasalahan kompleks dan dapat menimbulkan disorientasi ruang bagi para pengunjung ataupun pasien. Rawat jalan adalah salah satu unit pelayanan masyarakat yang bergerak di bidang kesehatan. Fungsi instalasi rawat jalan adalah sebagai tempat konsultasi, penyelidikan, pemeriksaan dan pengobatan pasien yang membutuhkan waktu singkat untuk penyembuhannya.

\footnotetext{
* Corresponding author e-mail : andrivina1286@gmail.com
} 
Menurut Kaplan dalam Mayangsari (2003), banyak pihak pengelola rumah sakit pemerintah maupun swasta beranggapan bahwa pemulihan kesehatan hanya dapat dilakukan dengan jalan medis saja. Akan tetapi, kenyataannya tidak demikian. Salah satu faktor pendukung yang dominan bagi pemulihan kesehatan seseorang adalah faktor psikologis yang mempengaruhi penderita tersebut (Prasetya, dkk, 2014). Padahal Teori Supportive Design sangat jelas mengatakan bahwa semua perancangan fasilitas kesehatan seharusnya mengacu pada upaya yang mendukung penyembuhan pasien dan menjauhkannya dari stres (Ulrich, 1991). Pada kenyataannya, praktik di lapangan tidak jarang menunjukkan hal yang kontradiktif, faktor tersebut diabaikan dan dianggap tidak penting.

Di dalam sebuah lingkungan binaan seperti fasilitas kesehatan ini, elemen-elemen orientasi sangat dibutuhkan agar seseorang dapat mencapai tujuan yang diinginkannya. Wayfinding dapat didefinisikan sebagai kemampuan untuk menemukan jalan menuju suatu lokasi. Wayfinding merupakan aspek penting dalam desain fasilitas kesehatan untuk menjadi salah satu parameter utama kualitas fasilitas kesehatan tersebut.

Dari pengamatan peneliti terhadap kondisi faktual poliklinik RSIA Limijati Bandung, terdapat beberapa gejala yang berpotensi menyebabkan masalah wayfinding pada poliklinik ini. Yang pertama yaitu ruang pendaftaran, ruang tunggu, poliklinik, farmasi, dan laboratorium yang terletak di lantai yang sama tanpa adanya batasan ruang dapat menyebabkan disorientasi terhadap pasien maupun pengunjung. Kedua, di beberapa titik juga sering ditemukan kepadatan pasien dan pengunjung yang tentu akan berimplikasi pada terhalangnya ruang pandang subyek terhadap titik atau lokasi yang dituju.

Proses wayfinding sangat membutuhkan input berupa Environmental Information (Informasi dari Lingkungan). Informasi ini dapat berupa signs, directories, maps, and cues from natural or manmade environment (atau tanda-tanda, direktoridirektori, peta-peta, penanda-penanda lainnya dari lingkungan alami atau lingkungan buatan manusia atau arsitektural) (Passini, 1984).

Di era BPJS Kesehatan ini, kepuasan pasien menjadi salah satu kunci keberhasilan fasilitas kesehatan untuk survive. Isu ini yang kemudian menjadi dasar pertimbangan penulis untuk memilih Poliklinik RSIA Limijati Bandung untuk memecahkan permasalahan disorientasi yang ada sekaligus mengoptimalisasikan sistem wayfinding di Poliklinik RSIA Limijati Bandung.

\section{Wayfinding dan Orientation System}

Wayfinding dapat didefinisikan sebagai kemampuan untuk menemukan jalan menuju suatu lokasi. Sedangkan Spatial Orientation adalah kemampuan seorang individu untuk memahami ruang di sekitarnya dan meletakkan dirinya. Seringkali individu tidak dapat menentukan posisinya dalam lingkungan tetapi dapat menemukan jalan ke sebuah lokasi, sehingga individu tetap berorientasi pada lingkungannya (Passini, R. 1984).

Menurut Golledge (1999), wayfinding adalah proses untuk menemukan dan mengikuti jalur atau rute di antara titik awal dan tujuan. Wayfinding adalah aktivitas yang dilatarbelakangi oleh motivasi, terarah, memiliki tujuan, dan dapat di observasi sebagai bukti dari tindakan sensorimotor di dalam sebuah lingkungan.

Dari definisi-definisi di atas dapat disimpulkan bahwa wayfinding merupakan perilaku bergerak dari satu tempat ke tempat lain, dari titik awal ke tempat tujuan, yang dilatarbelakangi oleh motivasi, rencana, memiliki tujuan, diupayakan secara efisien, dan dipengaruhi oleh lingkungan.

Passini (dalam Gunawan Tanuwidjaja, 2012) mencoba menjelaskan struktur Wayfinding dan Orientation Process (Proses Wayfinding dan Orientasi) dilakukan seorang individu untuk merangkum semuanya. Proses ini dijelaskan pada Gambar 1.

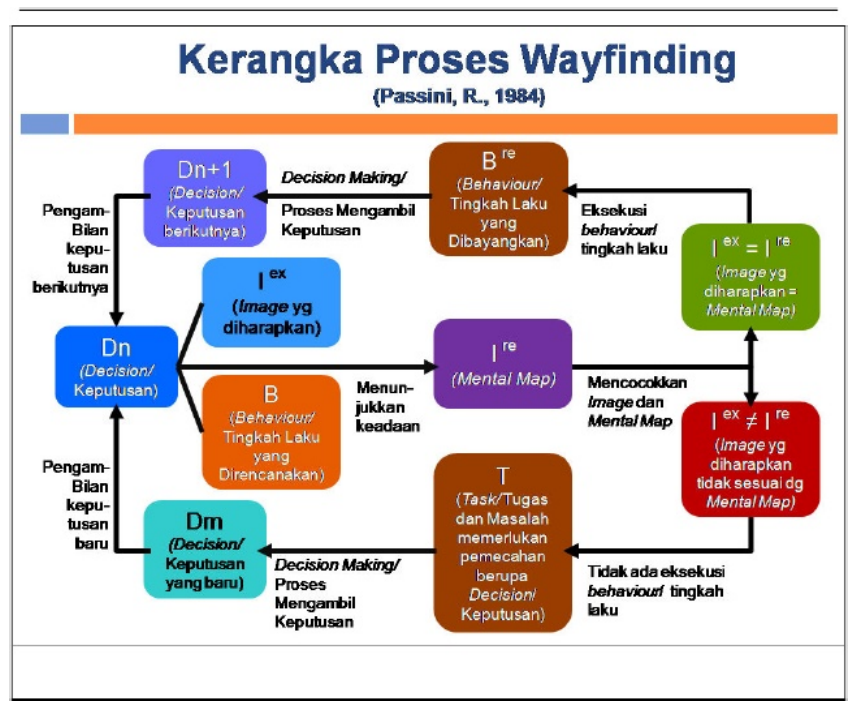

Gambar 1. Kerangka Teori Proses Wayfinding. Sumber: Passini, 1984, pp. 74

Passini (dalam Agus dkk., 2012) menjelaskan bahwa proses wayfinding ini terdiri dari 3 bagian penting diantaranya ialah pemrosesan informasi, pengambilan keputusan, dan tindakan aksi. Hal ini dapat dijelaskan sebagai berikut: Seorang individu 
memiliki sebuah Expected Image (image/citra yang diharapkan) dan Behaviour (tingkah laku yang direncanakan). Expected Image merupakan bayangan tempat tujuan atau perjalanan itu sedangkan Mental Map merupakan kondisi lingkungan yang diamatinya dari lingkungan. Proses wayfinding dilakukan dengan mencocokkan Expected Image $\left(\mathrm{I}_{\mathrm{ex}}\right)$ dengan Mental Map ( $\left.\mathrm{I}_{\mathrm{re}}\right)$ maka individu akan mencapai tujuan. Sebaliknya jika tidak, ia akan merencanakan tindakan lainnya untuk mencapai tujuan akhirnya. Sehingga interaksi antara manusia, proses persepsi dan elemen lingkungan sekitarnya sangat erat.

Menurut David Gibson (2009) dalam bukunya yang berjudul The Wayfinding Handbook Information Design for Public Space, signage dibagi menjadi beberapa kategori yaitu: (1) Identification Sign, Penanda visual yang menam pilkan nama dan fungsi sebuah tempat atau ruang; (2) Directional Sign, Merupakan sistem peredaran karena memberikan isyarat yang penting bahwa pengguna harus terus bergerak setelah mereka telah memasuki ruang; (3) Orientation Sign, Tanda-tanda orientasi dibuat agar pengunjung melihat gambaran lingkungan tempat tersebut dalam bentuk peta yang komprehensif dan memuat direktori; dan (4) Regulatory Sign, Tanda regulasi menjelaskan hal yang boleh dan yang tidak boleh dilakukan di tempat tertentu.

Craig M. Berger (2005) menyebutkan bahwa lokasi penempatan signage ditentukan oleh hasil analisa rute sirkulasi dan titik dimana terjadi decision point atau titik keputusan pengunjung pada suatu tempat. Peletakan signage secara vertikal juga perlu diperhatikan dari letak ketinggian serta ukuran font yang digunakan. Ketinggian yang baik dalam peletakan signage system yaitu sebesar $10^{\circ}$ dari sudut pandang pengguna.

\section{Perilaku dan persepsi manusia atas lingkungan}

Lingkungan fisik terdiri atas seperangkat permukaan dengan berbagai kualitas. Kadangkadang suatu lingkungan dirancang untuk tujuan estetika semata. Akan tetapi, pada umumnya tujuan perancangan suatu lingkungan adalah untuk memenuhi aktivitas tertentu. Salah satu cara bagi para perancang lingkungan untuk memenuhi tuntutan aktivitas tersebut adalah dengan mengacu pada sistem aktivitas yang terdiri atas suatu sirkuit perilaku (Perin, 1970 dalam Joyce Marcella Laurens, 2004).

Piaget (1996) menyatakan bahwa hubungan antara manusia dengan lingkungannya adalah identik dengan hubungan antara kognisi dengan struktur lingkungannya. Konsep ini ditunjukkan pada Gambar 2.

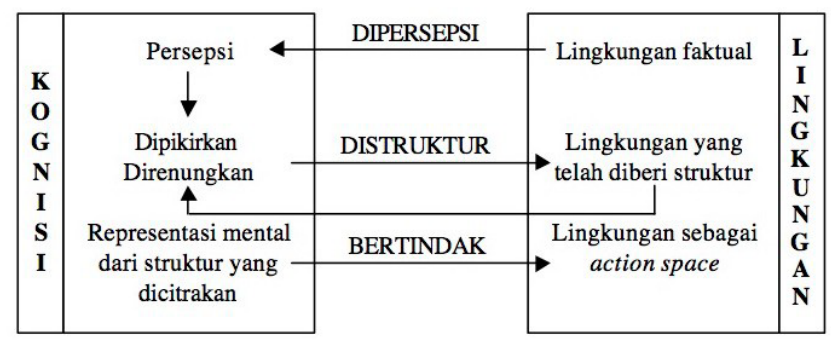

Gambar 2. Diagram hubungan antar manusia dengan lingkungannya (Sumber: Piaget, 1996)

\section{Bahan dan metode}

Lingkungan mengandung stimulus atau rangsang yang kemudian akan ditanggapi oleh manusia dalam bentuk respon tertentu. David Haviland (dalam Joyce Marcella Laurens, 2004) memakai istilah "ruangaktivitas" untuk menggambarkan suatu unit hubungan antara perilaku dan lingkungan bagi perancangan arsitektur. Konsep ruang aktivitas dan tata perilaku dapat dikatakan sama.

Sedangkan persepsi didefinisikan sebagai bagian dari proses kehidupan yang dimiliki oleh setiap orang, dari pandangan orang pada titik tertentu, lalu orang tersebut mengkreasikan hal yang dipandangnya untuk dunianya sendiri, kemudian orang tersebut mencoba mengambil keuntungan untuk kepuasannya (William Ittelson dalam Lang 1987, dalam Afifah dkk., 2008).

\section{Sirkulasi dan Permasalahan Wayfinding pada Rumah Sakit}

Rumah sakit adalah tipe bangunan yang memiliki banyak pengguna yang harus dipenuhi dan dipuaskan kebutuhannya. Semua pengguna di dalam rumah sakit tersebut melakukan pergerakan yang menggunakan elemen-elemen sirkulasi. Semakin banyak pengguna maka semakin banyak pula kompleksitas sirkulasi yang terjadi.

Dari standar dan kriteria sirkulasi serta permasalahan wayfinding yang telah disebutkan, fasilitas kesehatan yang baik juga harus didukung adanya kemudahan mencari sebuah titik dan penanda di bangunan tersebut, mengingat fasilitas kesehatan mewadahi berbagai kegiatan dan digunakan oleh pengguna yang "understress".

Menurut Canter and Canter, Petrie, Remen, dalam Carpman (2016), kualitas lingkungan fisik adalah hal yang sangat penting karena aspek terapeutik dalam di dalam desain fasilitas kesehatan juga harus 
dipertimbangkan. Desain fasilitas seperti sistem wayfinding, fitur desain universal, pengaturan furnitur, ketersediaan jendela, dan akomodasi terhadap anggota keluarga merupakan bagian dari perjalanan pasien menuju masa pemulihan.

Seperti yang sudah disebutkan bahwa kemudahan pasien dan pengunjung dapat mempengaruhi tingkat stres mereka, bangunan yang besar dan kompleks seperti rumah sakit terasa seperti di labirin terutama untuk pasien dan pengunjung yang jarang mengujungi fasilitas ini. Tidak dapat menemukan tujuan dapat menyebabkan perasaan tidak berdaya dan frustasi. Signage dapat membantu, tetapi mereka harus bekerja sama dengan fitur lain sebagai bagian dari sistem wayfinding yang terkoordinasi (Carpman and Grant, dalam Carpman, 2016).

Penelitian ini menggunakan metode kualitatif dengan analisis deskriptif. Analisis deskriptif adalah suatu metode dengan jalan mengumpulkan data, mengklarifikasi dan menginterpretasikannya. Tahapan pada penelitian, yaitu: (1) Pengumpulan kajian pustaka mengenai wayfinding, (2) Pengumpulan data dan temuan fakta tentang wayfinding di poliklinik RSIA Limijati Bandung, (3) Perbandingan objek penelitian dengan kajian pustaka, (4) Penarikan Kesimpulan.
Metode yang dipilih dalam penelitian ini adalah metode Post Occupancy Evaluation (POE) (Friedman, Zimring, \& Zube, 1978) terutama dengan direct observation dilakukan pada saat pengumpulan data mengenai elemen wayfinding yaitu peletakan signage sebagai elemen interior.

\section{Hasil dan pembahasan}

Di kota Bandung terdapat beberapa rumah sakit ibu dan anak yang dimiliki oleh pemerintah maupun swasta berdasarkan kelasnya. RSIA Limijati merupakan salah satu rumah sakit swasta yang berada pada target konsumen menengah ke atas. Rumah sakit ibu dan anak yang terletak di Jl. R.E. Martadinata No.39, Citarum, Bandung ini memiliki beberapa fasilitas yaitu layanan unggulan seperti Bandung Fertility Center (BFC), Limijati Hearing Center, dan Klinik Tumbuh Kembang (KTK). Rumah sakit ibu dan anak ini juga memiliki fasilitas lain yaitu rawat inap dan rawat jalan (Gambar 3).

Studi dilakukan pada poliklinik salah satu rumah sakit ibu dan anak di Kota Bandung, yaitu RSIA Limijati. Lingkup pengamatan dibatasi pada area poliklinik yang banyak dilalui oleh pengunjung.

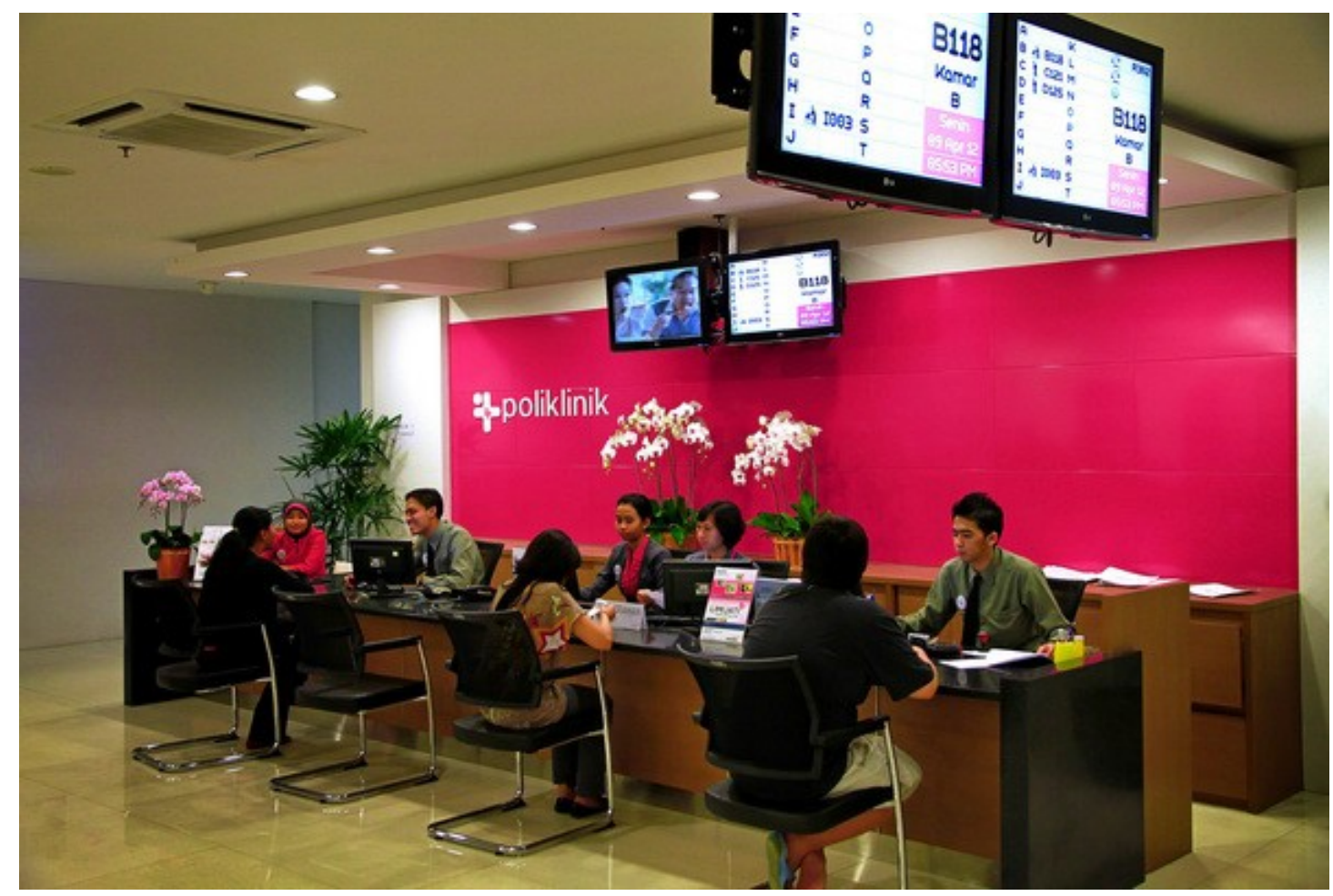

Gambar 3. Poliklinik RSIA Limijati Bandung.

(Sumber : http://rsia-limijati.com/) 
Pada tahap persiapan dilakukan kunjungan keliling di area poliklinik, rekam foto dan pengumpulan dokumen untuk mendapatkan gambaran kondisi fisik poliklinik. Pada tahap pelaksanaan dilakukan pengumpulan data primer. Tahap analisis data dilakukan dengan memfokuskan pada alur pergerakan pengunjung poliklinik pada saat melakukan wayfinding.

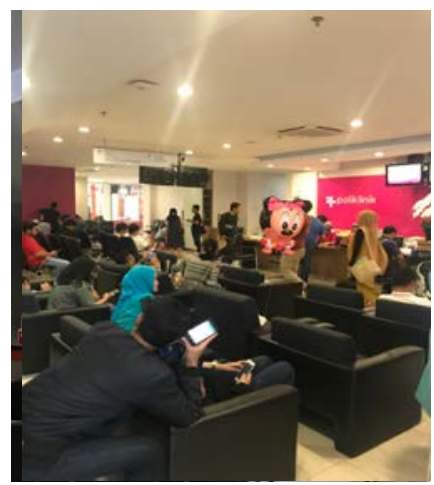

Gambar 4. Signage RSIA Limijati Bandung.

(Sumber: Dokumentasi Pribadi)

Pintu masuk area poliklinik RSIA Limijati dibagi menjadi dua yaitu dari arah area entrance utama dan basement yang melalui lift. Di area poliklinik RSIA Limijati Bandung secara keseluruhan wayfinding terletak di dalam ruangan (interior sign). Wayfinding pada area poliklinik tersebut rata-rata berada di depan dan di persimpangan masing-masing unit pelayanan. Penempatan desain wayfinding secara menggantung pada langit-langit di depan dan di persimpangan unit pelayanan juga sudah sesuai standar menurut Follis, J and Hamer, D. (1979), bahwa berdasarkan pertimbangan dalam pembuatan tanda baik di dalam ruangan (interior sign) maupun di luar ruangan (exterior sign), yaitu diletakkan dengan ketinggian mendekati $200 \mathrm{~cm}$.

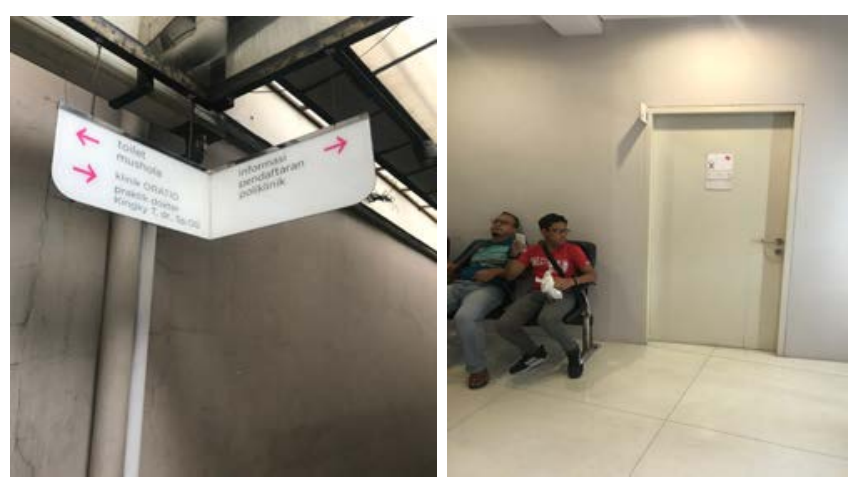

Gambar 5. Signage System dan Identification Sign RSIA Limijati Bandung. (Sumber: Dokumentasi Pribadi)
Pada area poliklinik terdapat beberapa signage system yang sudah dipasang di beberapa titik. Signage system tersebut ada yang berupa penunjuk arah ruangan (wayfinding) dan penamaan ruang (identification sign) seperti tampak pada Gambar 4.

Dari entrance utama, arah yang dituju diantaranya ialah pos satpam, loket pendaftaran, area ruang tunggu, customer service, retail, ruang periksa, kasir, dan farmasi. Sedangkan kemungkinan pengunjung yang berasal dari basement ialah ruang tunggu, ruang periksa, area servis seperti toilet dan musholla (Gambar 5). Berdasarkan observasi dan interview, pengunjung yang sudah mengenal situasi tidak banyak menunjukkan perilaku mundur kembali (backtracing), berhenti dan melihat-lihat, ataupun kesalahan berbelok. Perilaku tersebut lebih tampak pada pengunjung yang baru mengenal. Perilaku yang cukup sering terlihat adalah berhenti dulu dan melihat-lihat (stopping and looking).

\section{Kesimpulan}

Permasalahan wayfinding yang sering ditemui di fasilitas kesehatan adalah (Carpman dalam Wiranti, 2000: 98):

1. Wilayah di luar kompleks rumah sakit, seperti: Jalan utama yang menuju ke bangunan rumah sakit yang dituju tidak jelas karena tidak diberi nama; dan Posisi bangunan rumah sakit yang hendak dituju tidak jelas dan tidak ada ramburambu yang menunjukkan adanya suatu rumah sakit di dalam suatu lingkungan.

2. Wilayah di dalam kompleks rumah sakit, seperti pintu masuk ke dalam bangunan tidak cukup jelas; Dept. UGD terletak di lokasi yang sulit ditemukan atau jauh dari pintu utama; pepohonan seringkali menyembunyikan sign-sign penting dan menghalangi view ke arah pintu masuk utama; dan kurangnya perhatian terhadap fasilitas wayfinding di malam hari.

3. Permasalahan dalam kaitannya dengan arsitektur, seperti pintu masuk utama sulit dibedakan; bangunan yang sulit dibedakan dengan bangunan yang ada di sekitarnya; sirkulasi interior terlalu rumit atau terlalu kompleks dan membentuk sudut- sudut yang aneh; dan tidak bisa membedakan perbedaan antara pintu masuk utama dan pintu masuk pendukung. Pada fasilitas kesehatan, seringkali pintu masuk utama dibuat formal, bagus dengan lobby yang menarik, tetapi sebagian besar orang datang memarkirkan kendaraannya di tempat parkir struktural (bukan tempat parkir utama yang 
ditujukan untuk pasien dan pengunjung) dan masuk melalui pintu masuk fungsional (pendukung). Di sekitar pintu belakang tersebut tidak disediakan fasilitas customer-service dan pelayanan seperti yang disediakan di lobby utama.

4. Permasalahan dalam kaitannya dengan desain interior, seperti kurangnya koordinasi antara sistem pencahayaan dengan sistem signage; koridor publik tidak dibedakan dengan koridor staff; dan wayfinding landmarks yang disediakan terlalu sedikit.

5. Permasalahan dalam kaitannya dengan signage, seperti identifikasi yang menjelaskan institusi sangat minim; pengidentifikasian elevator sangat minim. Elevator tidak dilengkapi dengan identifikasi yang jelas, misalnya mengenai tujuan elevator tersebut (hanya untuk lantai 2 sampai dengan lantai 6 , sedangkan jumlah lantai keseluruhan ada 10 lantai), atau tidak menegaskan siapa yang berhak memakai elevator tersebut (staff vs publik); dan tidak mengkoordinasikan sign dengan elemen desain lainnya seperti detektor asap dan sprinkler heads.

Wayfinding di fasilitas kesehatan merupakan hal yang kompleks. Untuk itu dibutuhkan penanda (signage) yang dapat membantu pengunjung dan pasien rumah sakit dalam mendapatkan kemudahan untuk berorientasi dan menemukan tempat yang dituju. Dari hasil observasi dan wawancara terhadap pasien dan pengunjung, signage yang ada sekarang sudah cukup efektif dari segi peletakannya. Tetapi beberapa signage ditempatkan pada jarak yang tinggi secara vertikal dengan font yang kecil sehingga menyebabkan ketidakjelasan informasi dan tingkat keterbacaan yang rendah. Hal ini yang kemudian menyebabkan masih banyaknya pengunjung dan pasien yang bertanya kepada petugas ataupun satpam dalam menemukan tempat tujuannya.

Penerapan wayfinding pada interior memiliki tujuan untuk memberikan informasi dengan menggunakan signage yang didukung dengan peletakan sesuai lokasi ataupun tata ruang dan didukung dengan teks yang padat, jelas, dan singkat. Hal tersebut akan memudahkan pengunjung ataupun pasien dalam mencari lokasi terlebih untuk pengunjung baru. Sedangkan untuk pengunjung ataupun pasien lama akan menciptakan suasana dan alur sirkulasi poliklinik yang lebih efektif.

\section{Daftar pustaka}

Berger, Craig. (2005). Wayfinding, Designing and Implementing Graphic Navigational System. Switzerland: Roto Vision

Carpman, J.R. and Grant, M.A. (1993). Design That Cares: Planning Health Facilities for Patients and Visitors. Chicago: American Hospital Publishing.

Follis, dkk. 1979. Architectural Signing and Graphies. New York; Whitney Library of Design.

Gibson, David. (2009). Wayfinding Handbook: Information Design for Public Places. New York: Princeton Architectural Press

Golledge, R. G. (Ed.). (1999). Wayfinding behavior: Cognitive mapping and other spatial processes. Baltimore: John Hopkins University Press.

Mayangsari, Sriti. (2003). Peran warna pada interior rumah sakit berwawasan 'healing environment' terhadap proses penyembuhan pasien. Dimensi interior Vol. 1 No. 2, Desember 2003: 141-146.

Passini, R. (1984). Wayfinding in Architecture, Environmental Design Series Volume 4. New York: Van Nostrand Reinhold.

--------, R. (1992). Wayfinding in Architecture. New York: Van Nostrand Reinhold.

Prasetya, R. D., Laedpriwan, S., \& Wanichakorn, A. (2014). Visiting patient activity at patient room in the perspective of Thai people. Journal of ASEAN Research in Arts and Design, 1(2), 26-34.

Tanuwidjaja, Gunawan. (2012). Tinjauan Pustaka Wayfinding \& Orientation System

Ulrich, R. S. (1991). Effects of interior design on wellness: theory and recent scientific research. Journal of Health Care Interior Design: Proceedings from the ... Symposium on Health Care Interior Design. Symposium on Health Care Interior Design, 3, 97-109. Retrieved from http://www.ncbi.nlm.nih.gov/pubmed/10123973 